\title{
Teoría y práctica decolonial: un examen crítico
}

"el lector debe estar preparado para advertir sin sorpresa que los problemas que aquí se estudian desbordan por todos lados

los límites concretos del tema americano, para acabar ofreciendo una idea de la marcha y progreso de la Cultura de Occidente, que así se revela como el único proyecto vital de la historia con verdadera promesa en virtud de la dialéctica interna que lo vivifica."

Edmundo O' Gorman, La invención de América, 1958.

Expresiones como ésta son una muestra clara de la fascinación por lo europeo (occidental), tan propia de quizá la mayor parte de la intelectualidad de países y pueblos antaño colonizados. Roto el colonialismo político, sobrevive un colonialismo cultural e intelectual (dejemos por ahora a un lado la espinosa cuestión de la economía). Aunque expresiones como la citada sería hoy extraño leerlas en textos académicos, versiones atenuadas, expresadas en términos algo más "políticamente correctos", continúan presentes y actuantes. El prejuicio explícito o implícito de que todo lo que viene de Europa o Norteamérica es mejor, la tendencia a reproducir acríticamente los discursos y las prácticas de allí provenientes, el sentimiento de inferioridad, el énfasis en la repetición de verdades recibidas antes que en el desarrollo de un pensamiento original, la ceguera ante las diferentes manifestaciones de "colonialismo interno", el desprecio hacia (y la incomprensión de) el sentir y el pensar de las clases populares y los pueblos originarios y el "racismo" abierto o solapado son, ciertamente, rasgos muy fuertemente extendidos entre académicos e intelectuales. También es indudable la existencia de inauditos privilegios epistémicos. Una obra escrita en inglés tiene muchísima más chance de ser conocida y reconocida que una escrita en castellano ( $i y$ ni hablar si lo es en quechua o mapuzugun!) con independencia de sus cualidades intrínsecas. Del mismo modo, un prejuicio común y ampliamente extendido presupondrá que lo que dice un universitario debe ser correcto, sin evaluar sus argumentos; o asumirá que las afirmaciones de alguien con piel blanca y ojos claros son más creíbles que las de alguien de piel y ojos oscuros. Se entiende, pues, la reacción de intelectuales y activistas contra prejuicios tan groseros. En los

* Departamento de Historia, Universidad Nacional del Comahue, Argentina. https://orcid.org/0000-0003-2569-9180. últimos lustros una corriente teórica dispuesta a combatir lo que considera "colonialidad epistémica" viene ganando espacios y visibilidad en el mundo académico. Se trata de la denominada opción decolonial o, según la denominación reciente, descolonial.

Aunque quienes integran el autodenominado proyecto modernidad/colonialidad (Catherine Walsh, Walter Mignolo, Aníbal Quijano y Boaventura de Sousa Santos son acaso las figuras más conocidas) tienen significativas diferencias entre sí, comparten algunas premisas, cierto estilo intelectual y ciertos espacios y prácticas comunes, como para que sea razonable considerarlos una corriente intelectual.

Un buen resumen de las premisas compartidas nos lo proporciona Mignolo:

1. No existe modernidad sin colonialidad, ya que ésta es parte indispensable de la modernidad.

2. El mundo moderno/colonial (y la matriz colonial de poder) se origina en el siglo $\mathrm{XVI}$, y el descubrimiento/invención de América es el componente colonial de la modernidad cuya cara visible es el renacimiento europeo.

3. La llustración y la Revolución Industrial son momentos históricos derivados que consisten en la transformación de la matriz colonial de poder.

4. La modernidad es el nombre del proceso histórico en el que Europa inició el camino hacia la hegemonía. Su lado oscuro es la colonialidad.

5. El capitalismo, tal como lo conocemos, está en la esencia de la noción de modernidad y de su lado oscuro, la colonialidad.

6. El capitalismo y la modernidad/colonialidad tuvieron un 
segundo momento histórico de transformación después de la Segunda Guerra Mundial, cuando Estados Unidos se apropió del liderazgo imperial del que antes habían gozado, en distintas épocas, España e Inglaterra. ${ }^{1}$

Todas estas premisas son ciertamente debatibles, aunque a este nivel (extremo) de generalidad se las puede aceptar, quizá modificando los énfasis. ${ }^{2}$ Sin embargo, de ellas se extraen dos conclusiones mucho más polémicas. La primera es que la clave del dominio occidental es epistémica (antes que económica, tecnológica, política o militar). La segunda, derivada de la anterior, es que para poner fin a la colonialidad es indispensable una ruptura con los marcos epistémicos "occidentales": practicar un "desprendimiento epistémico", para decirlo en sus propios términos. $^{3}$ 18.

2 Subrayemos incidentalmente, sin embargo, que incluso en un texto tan breve se observan significativas inconsistencias en el tratamiento, algo que parece caracterizar al estilo decolonial producido hasta el momento. Por ejemplo, la primera premisa considera que el mundo moderno/ colonial se origina en el siglo $\mathrm{XVI}$, y que el descubrimiento/invención de América es el componente colonial de la modernidad cuya cara visible es el renacimiento europeo. Sin embargo, el Renacimiento comenzó en 1300 o 1400 (no hay consenso al respecto), es decir uno o dos siglos antes del inicio del mundo moderno/colonial. Además, la insistencia en la ruptura del siglo XVI parece tener un sesgo "hispanocéntrico" que oscurece la gran expansión portuguesa en África y el Lejano Oriente, iniciada en 1415 (debo agradecer a Federico Mare el haber llamado mi atención sobre esta "precocidad" portuguesa). En la tercera premisa se señala que la llustración y la Revolución Industrial son momentos históricos derivados que consisten en la transformación de la matriz colonial de poder. Pero en la sexta se nos informa que el capitalismo y la modernidad/colonialidad tuvieron "un segundo momento histórico de transformación después de la Segunda Guerra Mundial, cuando Estados Unidos se apropió del liderazgo imperial del que antes habían gozado, en distintas épocas, España e Inglaterra" (la hegemonía holandesa es olvidada). ¿No sería en todo caso un tercer momento histórico, si la Ilustración y la industrialización fueron otro? Pero sobre todo ¿por qué elegir como momentos relevantes justamente a ésos, tan eurocéntricos u occidentalocéntricos? ¿La independencia de las colonias americanas (del norte y del sur) no fue otro momento histórico equivalente? ¿Y la Revolución Rusa, la china, la independencia de la India, la descolonización de África, etc., etc.?

3 El contenido conceptual de "desprendimiento" no ha sido precisado. $\mathrm{Da}$ a entender que se deberían abandonar todas las pautas epistémicas supuestamente occidentales, cuyo contenido es objeto de una no meno imprecisión: se asume el supuesto no fundamentado de que Platón y Derrida, Santo Tomás y Foucault, Marie Curie y Nietszche, Marx y Walras, Einstein y Abelardo, Eric Wolf y Ginés de Sepúlveda, Otto Bauer y Goebbels (y la lista podría seguir indefinidamente) comparten un mismo marco epistémico. Muchas veces, los partidarios de la opción decolonial arguyen que "desprendimiento" no es un concepto, sino una propuesta política (lo ha hecho por ejemplo un/a evaluador/a anónimo/a de este escrito). El problema es que lo segundo no hace innecesario lo primero. "Socialismo" es también una propuesta política, y sin embargo hay conceptualizaciones bien claras del mismo, y bien diversas (pero por ser claras pueden ser evaluadas y discutidas apropiadamente).

\section{Etnicidad y colonialidad}

Es indudable que existen abismales diferencias de poder, y que una dimensión de las mismas posee un carácter étnico. Ello no significa, empero, que las diferentes etnias posean necesariamente culturas claramente diferenciadas. Aunque ciertos rasgos culturales más o menos diferenciales pueden ser precondiciones de la etnicidad, ésta tiene que ver con la identidad; y se puede tener identidades diferentes sin ninguna diferencia observable en la cultura o forma de vida. Si se me permite decirlo un tanto provocadoramente, hoy en día no es claro que exista una cultura mapuche, como tampoco una cultura argentina, chilena o europea. Lo que hay, sin dudas, son identidades mapuche, argentina, chilena, estadounidense, española, etc. $Y$ también, desde luego, manifiestas diferencias de poder, riqueza y estatus entre estos diferentes grupos étnicos, sin que necesariamente sus formas de vida difieran demasiado. Las fronteras culturales son cada vez más borrosas: el mundo es cada vez más mestizo (aunque, y no es menor, las influencias relativas de cada tradición cultural son muy asimétricas). El poeta mapuche Erwin Quintupil captó perfectamente la tendencia al mestizaje cultural unida a la pervivencia e incluso reforzamiento de las identidades, en medio de la descomunal asimetría entre los diferentes estados o culturas a la hora de crear bienes culturales que son impuestos a otros o aceptados por éstos más o menos voluntariamente. En el poema titulado "Sin nombre" (1995) escribió:

\author{
Hay chilenos que dicen \\ que si soy indígena \\ por qué uso entonces jeans. \\ A mí me dan \\ ganas de decirle \\ que ni él ni yo somos made in USA.
}

La interculturalidad implica el respeto mutuo entre las diferentes identidades, se funden o no en importantes diferencias culturales. Las identidades son realidades simbólicas que no remiten a ninguna esencialidad no simbólica. Los bienes culturales pueden tener origen o un mayor desarrollo en el marco de ciertas culturas o grupos identitarios, pero no pertenecen exclusivamente a ellos. El jean tiene origen en Estados Unidos, pero no pertenece a los estadounidenses intrínsecamente. Cuando hablamos de cosas tales como "literatura inglesa", "arte maya" o "tecnología china" deberíamos tener en cuenta que son formas de referirse a la literatura, el arte o la tecnología producidas en un espacio geográfico determinado o en una lengua específica, y no a una literatura, un arte o una tecnología que posea esenciales, absolutamente propias e inmodificables, características inherentes.

Así, no existe una episteme intrínsecamente occidental. Y sería 
absurdo y poco respetuoso pedirle a alguien que abandone su identidad occidental, si la tuviera, como en su momento fue absurdo (y en algunos casos lo sigue siendo) exigirles a las poblaciones originarias que abandonen su lengua y creencias. Lo apropiado, en todo caso, sería pedirle a quien sea que abandone los aspectos injustificables de sus creencias. No necesitamos conversiones religiosas ni genéricos "desprendimientos". Lo que necesitamos es desarrollar el pensamiento crítico. ¿Cómo se presenta la opción decolonial ante una inspección crítica? Veamos.

Comencemos por el concepto de colonialidad, que es en cierto modo el concepto madre. Según Aníbal Quijano:

Colonialidad es un neologismo necesario. Tiene respecto del término colonialismo, la misma ubicación que modernidad respecto de modernismo. Se refiere, ante todo, a relaciones de poder en las cuales las categorías de "raza", "color", "etnicidad", son inherentes y fundamentales.

Estas líneas son mucho más problemáticas de lo que podría parecer a primera vista. En primer lugar, el paralelismo que se traza entre modernidad/modernismo y colonialidad/colonialismo no parece válido, en los propios términos de Quijano. Convencionalmente, por modernismo se entiende un estilo artístico o intelectual, y por modernidad un período histórico en el que dicho estilo sería dominante. Por consiguiente, la colonialidad debería referirse a un período histórico en el que domina el colonialismo. Pero no es el caso:

Colonialidad es un concepto diferente, aunque vinculado con el concepto de colonialismo. Este último se refiere estrictamente a una estructura de dominación y explotación, donde el control de la autoridad política, de los recursos de producción y del trabajo de una población determinada lo detenta otra de diferente identidad, y cuyas sedes centrales están, además, en otra jurisdicción territorial. Pero no siempre, ni necesariamente, implica relaciones racistas de poder. El colonialismo es, obviamente, más antiguo, en tanto que la colonialidad ha probado ser, en los últimos quinientos años, más profunda y duradera que el colonialismo. Pero sin duda fue engendrada dentro de este $y$, más aún, sin él no habría podido ser impuesta en la intersubjetividad del mundo, de modo tan enraizado y prolongado. 5

4 Aníbal Quijano, "América Latina en la economía mundial" [1993], Cuestiones y horizontes. Antología esencial, Buenos Aires, Clacso, 2014, p. 206, nota 3.

5 Aníbal Quijano, "Colonialidad del poder y clasificación social" [2000], op. cit., p. 285, cita a pie (destacado en original). Tomo aquí la definición de colonialismo del propio Quijano. Obviamente, los fenómenos históricos subyacentes son bastante diversos y un tratamiento más detallado de esta problemática entrañaría establecer distinciones entre diferentes conceptos indudablemente relacionados, tales como: colonialismo, imperialismo, colonialismo naval, imperialismo territorial, colonias de explotación, colonias de asentamiento, imperialismo de tipo antiguo, imperialismo capitalista, etc. Pero de nada de esto se ocupa Quijano.
Definido en tales términos (que son los convencionales, por lo demás), el colonialismo es milenario y transcultural: hubo colonialismo persa, romano, islámico o inca, entre muchísimos otros. Si es anterior o no a la colonialidad (entendida como relaciones de poder en las cuales las categorías de "raza", "color" y "etnicidad" son inherentes y fundamentales), es cosa que habría que demostrar, pero parece altamente probable que existieran formas de colonialidad (es decir, alguna forma de opresión por parte de un grupo étnico sobre otros) anteriores al colonialismo en estricto sentido. Ahora bien, si el colonialismo es anterior a la economía mundo (moderna/colonial) que se configuró hacia el siglo $\mathrm{XVI}$, y la colonialidad un fenómeno capaz de sobrevivir al colonialismo (y quizá anterior a él), entonces cabe preguntarse en qué consiste exactamente ese "patrón colonial" de poder del que nos habla Quijano. Porque si se lo define genéricamente ("relaciones de poder en las que la raza, el color o la etnicidad son fundamentales") esa matriz es muy anterior al siglo XVI. Ni el colonialismo ni la colonialidad son una novedad de los tiempos de Colón y Moctezuma. En cualquier caso, lo que acontece en el siglo XVI es que el colonialismo y la colonialidad adoptan formas específicas (en las que Quijano no abunda), por un lado, y una magnitud incomparable con el pasado, por otro. Pero, obviamente, ni esa especificidad ni esa magnitud pueden ser explicadas por la propia colonialidad: los europeos no lograron cuasi-dominar al mundo por haber inventado el colonialismo y la colonialidad (que ya existían). Lo que hicieron fundamentalmente fue llevar el colonialismo y la colonialidad a una escala sin precedentes. ¿Cómo fue esto posible? Los debates al respecto son enormes. Algunos insistirán en el desarrollo de las relaciones capitalistas de producción, otros en la Revolución Industrial, otros en el pensamiento científico, etc. Sin necesidad de una crítica pormenorizada de todas esas perspectivas, los autores y autoras decoloniales insisten en que la clave es epistémica. Mignolo por ejemplo afirma:

El problema, para el marxismo, es el capitalismo; mientras que para la opción decolonial lo es la matriz (patrón en el vocabulario de Aníbal Quijano) colonial de poder, de la cual la economía es una esfera. El marxismo se afinca en la forma que adquiere la matriz colonial en el siglo XVIII (y se enfoca en el aspecto económico). La opción decolonial se afinca en la formación histórica de la matriz colonial de poder en el siglo XVI (y se enfoca en la gestión de la economía, de la autoridad, del género y la sexualidad; de la subjetividad y el conocimiento), y hace del control del conocimiento el instrumento fundamental de dominio y control de todas las otras esferas. ${ }^{6}$

Sin embargo, su perspectiva nada tiene que ver con otras explicaciones epistémicas o cognitivas del tipo de las que

6 W. Mignolo, "La idea de América Latina ("La derecha, la izquierda y la opción decolonial)", en Crítica y Emancipación $n^{\circ} 2,1^{\circ}$ semestre de 2009, p. 254 (destacado en original). 
proporciona por ejemplo Ernest Gellner, para quien fue el desarrollo del conocimiento científico, con toda su compleja especificidad, lo que permitió a quienes eran capaces de dominar sus técnicas (algunos países de Europa primero, Estados Unidos después) desarrollar capacidades económicas, navales y militares inalcanzables para el resto. ${ }^{7}$ No sería, pues, la eficacia cognitiva de la ciencia y sus aplicaciones tecnológicas la clave del dominio occidental. La clave sería el colonialismo y la colonialidad impuestos por medio de lo que Mignolo llama "retórica de la modernidad". Pero esto en verdad no explica nada y si lo hace, no deja bien parados a los pueblos colonizados. Detengámonos, pues, en esta pretendida explicación. Según Mignolo:

a partir de 1500, otomanos, incas, rusos, chinos, etcétera, comenzaron a enfrentarse con un proceso de inversión del reconocimiento: comenzaron a reconocer que las lenguas occidentales y las categorías de pensamiento y, por lo tanto, la filosofía política y la economía política se expandían sin reconocer-les a ellos como iguales en el juego. ${ }^{8}$

Esto es cierto en general, desde luego. Pero, ¿por qué querrían los otomanos, los chinos o los incas preocuparse por cosas como la filosofía política, sin las cuales habían vivido hasta entonces tan plácidamente? ¿Y qué daba a la minoría europea el poder de decidir quién y cómo era reconocido? ¿Por qué era tan importante el reconocimiento europeo? ¿Por qué esa etnia (o conglomerado de etnias) particular podía ejercer tal influencia y poder de atracción? La respuesta es que los europeos habían desarrollado un salto abrupto, descomunal, en la productividad del trabajo y en las tecnologías bélicas, lo que les daba un poder incomparable. Las fuentes de este poder están en debate: ¿han sido el capitalismo, la manufactura/industria, la ciencia, la economía-mundo, la cristiandad? ${ }^{9}$ La respuesta decolonial (en esto hay acuerdo pleno entre quienes se reivindican decoloniales, sean cuales fueran sus diferencias en otros planos) insiste en que el fundamento es "epistémico", pero concibiendo lo epistémico no como capacidad cognitiva traducible en dominio técnico, sino en un sentido más bien retórico: la retórica de la modernidad habría exaltado todo lo occidental, clasificado racial o étnicamente a los grupos humanos e inferiorizado a las otras culturas. Esto es como decir que durante siglos hemos

7 Ernest Gellner, El arado, la espada y el libro. La estructura de la historia humana, Barcelona, Península, 1988.

8 W. Mignolo, Desobediencia epistémica. Retórica de la modernidad lógica de la colonialidad y gramática de la descolonialidad, Buenos Aires, Ediciones del Signo, 2010, p. 13 (destacado en original).

9 La literatura al respecto es inagotable, pero se pueden citar algunos trabajos clásicos: Kirti N. Chaudhuri, The Trading World of Asia and the English East India Company, 1660-1760, Cambridge, Cambridge University Press, 1978; Immanuel Wallerstein, El moderno sistemamundial, t.I, México, Siglo XXI, 1981; Eric Jones, The European Miracle: Environments, Economies, and Geopolitics in the History of Europe and Asia, Cambridge, Cambridge University Press, 1989; Kenneth Pomeranz, The Great Divergence: China, Europe and the Making of the Modern World Econmy, New Jersey, Princeton University Press, 2000. sido engañados, y que el poder de los dominadores reside en su capacidad para inculcarnos pensamientos que nos perjudican. Por lo demás, no parece una respuesta ni muy convincente en términos explicativos, ni que deje intelectualmente bien parados a los pueblos oprimidos, decir o implicar que, en lo fundamental, el dominio euro-norteamericano se debe a su capacidad para inculcar retóricamente concepciones que los benefician, antes que a su poderío militar y económico.

Desde luego que la ideología forma parte de la dominación, pero parece obvio que la misma tiene otras bases. Una crítica puntillosa de las otras explicaciones disponibles continúa ausente en la producción intelectual decolonial, a pesar de tener ya un par de décadas de desarrollo. Es aceptable (aunque no ineludible) que una concepción incipiente se dé a conocer por medio de críticas generales y poco desarrolladas a sus rivales intelectuales. Pero en algún momento la crítica rigurosa debería darse a conocer. Si esto no sucede, es difícil tomar teóricamente en serio a esa concepción; por importante que sea en términos retóricos. Podrá tener efectos sociales y políticos, pero ello no es equivalente a solvencia teórica.

\section{Privilegio y asimetría epistémicos}

Nada de esto implica negar ni la existencia ni la importancia del fenómeno de la colonialidad, entendido como formas de poder en las que la etnicidad resulta constitutiva y fundamental. En el terreno cognitivo, acabar con todas las formas de privilegio epistémico resulta ética y políticamente indispensable. Pero deberíamos tener presente que privilegio epistémico no es lo mismo que asimetría epistémica. Privilegio epistémico es que las concepciones de los miembros de un grupo o comunidad determinada tiendan a ser aceptadas o validadas sin previo examen y, a la inversa, que las concepciones de los miembros de otros grupos o comunidades tiendan a ser desvalorizadas sin examen o lisa y llanamente ignoradas. La asimetría es otra cosa: refiere al hecho puramente factual de que ciertos individuos poseen un conocimiento mayor (en ciertas materias o campos, y sólo en ellos) que otros. Pero la asimetría no debería conferir privilegio: que mi conocimiento sobre teoría de la historia sea mayor que el de mis estudiantes no significa que necesariamente mis pareceres sobre determinadas problemáticas del campo sean mejores. Eso, en todo caso, debería ser demostrado o cuando menos argumentado. En cuestiones de conocimiento, como en el fútbol, existen asimetrías pero, como se dice, los partidos hay que jugarlos y se ganan en la cancha.

La opción decolonial ataca fuertemente los privilegios epistémicos y en este punto estamos de acuerdo. Pero su rechazo a las fantasmagóricas "episteme occidental", "retórica de 
la modernidad" o "lógica de la colonialidad" es una verdadera ensalada conceptual, una bolsa de gatos en la que además todos los gatos parecen ser pardos. Si el planteo decolonial fuera a desnudar los contenidos etnocéntricos implícitos en cualquier marco teórico o epistémico, a criticar los errores cognitivos que dicho etnocentrismo pudiera producir y a denunciar las sutiles, y no tan sutiles, prácticas sociales y académicas que perpetúan privilegios, no podríamos más que coincidir. ${ }^{10}$ Pero, ¿por qué ello entrañaría desprenderse de un entero marco epistémico? ¿Y qué debemos entender por marco epistémico? ¿Por qué deberíamos salirnos de la retórica de la modernidad en vez de radicalizarla? ¿Qué es la "lógica de la colonialidad" de la que tanto hablan? ¿De qué deberíamos exactamente desprendernos? Como veremos más adelante, las respuestas decoloniales a estos interrogantes oscilan entre una respuesta radical pero teóricamente inconsistente y poco plausible, por un lado, y una respuesta sensata pero escasamente radical, por otro.

Por lo demás, la retórica del "desprendimiento epistémico" puede perpetuar e incluso acrecentar asimetrías epistémicas. Conviene no olvidar que en la sociedades divididas en clases los saberes se hallan muy desigualmente repartidos. En los planos simbólico, técnico y cognitivo, el dominio de las clases dominantes se funda en su capacidad para colocar bajo su órbita y trabajando para ellas a científicos, técnicos e intelectuales. Esto no significa, por caso, que todos los alemanes o yankees (de origen anglosajón) dominen esas técnicas y conocimientos. Para un obrero yankee el psicoanálisis, la economía neoclásica, la física cuántica o la matemática de conjuntos suelen ser concepciones tan ajenas como lo podrían ser para un mapuche (y hay mapuche que las dominan). Rechazar el doble privilegio epistémico, según el cual se asume prejuiciosamente que lo que diga un científico debe ser correcto no sólo en su campo de estudio específico sino en cualquier materia en general, es una tarea ineludible. Pero los llamados oscurantistas a desprendernos

10 Habría que señalar que así como nadie puede abordar ninguna realidad fuera de algún marco teórico, tampoco nadie puede desprenderse de ciertas características étnicas, de género o de clase. No hay ojo de Dios, mirada desde ninguna parte. Pero ello no significa que las miradas tengan el mismo grado de universalidad, así sea tendencial. El problema, pues, no es tanto el etnocentrismo (que en términos absolutos es ineliminable), sino el etnocentrismo que no se sabe tal (inconsciente de sí mismo) y los errores que las miradas etnocéntricas pueden acarrear. Pero al igual que las miradas políticas -que pueden tener tanto consecuencias negativas por entrañar ceguera o dogmatismo apologético cuanto producir efectos positivos como la visibilización de problemas no detectados o insuficientemente tratados-, las perspectivas étnicas no pueden ser eliminadas ni es deseable intentarlo. Por ello, no es suficiente como crítica a una teoría señalar cierto carácter etnocéntrico: hay que mostrar que ese etnocentrismo ha llevado a captar mal ciertos procesos o ciertas conexiones. Poco sensibles a la dimensión explicativa de los textos de filosofía y ciencias sociales que critican, los partidarios de la opción decolonial han cuestionado sobre todo ciertos aspectos de la implicación ideológica de tales textos, aunque casi siempre sin distinguir adecuadamente entre ambas dimensiones o tareas. Desde luego que no hay ningún tribunal de apelación último que determine sobre las virtudes relativas de las teorías. Pero, en todo caso, conviene recordar que el detectar cierto contenido etnocéntrico en una producción intelectual no invalida de por sí las hipótesis que contenga. de una episteme occidental -oscurantistas porque no arrojan ni un poco de luz sobre las descomunales diferencias teóricas existentes al interior de lo que se engloba como "occidental"ponen trabas al meticuloso estudio de campos tan diversos del saber, generando una falsa seguridad: aquellos que se sienten "desprendidos" creen poder refutar en cuatro frases y luego de unas pocas lecturas superficiales obras y tesis de gran complejidad. Un efecto parecido al que en la tradición marxista provoca la mitología sobre una metodología dialéctica que, se supone, los pensadores burgueses no pueden comprender."1 En un caso nunca se especifica en qué consiste exactamente esa metodología dialéctica que el enemigo de clase es incapaz de captar (más allá de generalizaciones pueriles como que "el todo es más que la suma de las partes" o que existen "saltos de la cantidad en calidad"); en el otro jamás se especifica en qué consiste exactamente esa episteme "occidental" causante de la colonialidad.

Quizá haya una retórica de la modernidad (en realidad hay varias); pero parece evidente que la modernidad no ha sido sólo retórica, y que si la modernidad/colonialidad europea tuvo la capacidad que tuvo para colonizar de manera directa a casi todo el mundo y para forzar cambios decisivos en las regiones no directamente colonizadas, ello seguramente se debió a que no era una mera retórica. La hegemonía europea pudo reforzarse retóricamente, pero tuvo fundamentos económicos, políticos y militares irreductibles a la retórica. Tuvo también componentes cognitivos (que no es lo mismo que retóricos). Sin la ciencia moderna no se hubieran desarrollado las tecnologías capaces de someter económica o militarmente al mundo no-europeo. Pero si la ciencia moderna ha tenido la capacidad de producir tan indudables transformaciones, es porque aunque su empleo político pueda tener contenidos tanto opresivos o liberadores, epistemológicamente es potente. En la imperdible conferencia "Reflexiones sobre una política de la ciencia", de mayo de 1979, Manuel Sacristán le dijo a su audiencia con aguda justeza:

me parece oportuno recordaros aquella frase de Ortega, en uno de sus últimos escritos, en un escrito póstumo, en la que después de examinar el cientificismo de algunos filósofos y hasta científicos de la primera mitad del siglo, principalmente físicos, concluye diciendo que de la Física han fracasado mil cosas, a saber, el fisicalismo, a saber, la metafísica fisicista, etc.

11 Afirmaciones como que el zapatismo habría producido una "revolución teorética" (W. Mignolo, Desobediencia epistémica, op. cit., p. 38) demuestran una ceguera políticamente motivada ( $y$ aclaro que la motivación política también puede ser luminosa, si no claudica en su criticidad) semejante a la de los marxistas que veían en Materialismo y empiriocriticismo de Lenin, una obra filosófica fundamental, creían que Stalin había revolucionado la lingüística o que las críticas a la lógica formal desplegadas por Trotski eran rigurosas. Quien sepa de filosofía, de lingüística y de lógica y mantenga el juicio crítico verá que esas son malas críticas. Así como para ser marxista no hace falta comprar tales buzones, no se necesita imaginar una "revolución teorética" para apoyar a los zapatistas. 
y entonces hace punto y dice, con su retórica generalmente graciosa (en este caso me parece que lo es): "Lo único que no ha fracasado de la Física es la Física", y no el especular prolongándola, no el hacer generalizaciones sobre la base del conocimiento físico.

Pues bien, yo también creo que eso es verdad, pero ocurre que en este final de siglo estamos finalmente percibiendo que lo peligroso, lo inquietante, lo problemático de la ciencia es precisamente su bondad epistemológica. Dicho retorciendo la frase de Ortega: lo malo de la Física es que sea buena, en cierto sentido un poco provocador que uso ahora. Lo que hace problemático lo que hacen hoy los físicos es la calidad epistemológica de lo que hacen. Si los físicos atómicos se hubieran equivocado todos, si fueran unos ideólogos pervertidos que no supieran pensar bien, no tendríamos hoy la preocupación que tenemos con la energía nuclear. Si los genetistas hubieran estado dando palos de ciego, si hubieran estado obnubilados por prejuicios ideológicos, no estarían haciendo hoy las barbaridades de la ingeniería genética. Y así sucesivamente. ${ }^{12}$

Sacristán era un filósofo que sabía qué es hacer ciencia rigurosa. Tenía una mirada crítica sobre la ciencia como producto cultural (la ciencia es un conjunto de teorías, pero como fenómeno no se agota en ellas: incluye también instituciones y prácticas); pero sin negar su potencia epistemológica y aceptando lo acotado del campo de validez de la ciencia como saber (además de su carácter relativo, no absoluto). Sacristán sabía que la ciencia no tiene respuestas para todo, que sus respuestas son siempre tentativas, y que hay preguntas que la ciencia ni puede responder ni es sabio pretender hallarles una respuesta científica (por ejemplo la pregunta por el sentido de la vida, que es más sensato abordarla filosófica o religiosamente). La suya es una excelente perspectiva, filosóficamente amplia, científicamente rigurosa, respetuosa de las diversidades culturales, de intencionalidad revolucionaria e irrenunciablemente crítica. ¿Deberíamos desprendernos de ella? ¿Por qué?

$\mathrm{Si}$-como expusiera Frantz Fanon- el pensamiento racista ha sustentado la "obscena idea" de que los "negros" y los "indios" son incapaces congénitamente de desarrollar la lógica y la ciencia, el riesgo implícito en perspectivas como la decolonial reside en instar a los miembros de grupos étnicos oprimidos a desconocer o rechazar las cualidades cognitivas de la lógica y la ciencia al verlas (equívocamente) como puras formas coloniales. ${ }^{13}$ Y conviene no olvidar que la lógica, el racionalismo y diferentes empresas de corte científico han sido desarrolladas fuera de Europa, en muchos casos de manera totalmente independiente. Como expusiera Federico Mare en una comunicación personal

12 Manuel Sacristán, Conferencias 1978-1983, Barcelona, El Viejo Topo, 2005, p. 62 (destacado en original).

13 Frantz Fanon, Los condenados de la tierra, México, Fondo de Cultura Económica, 2009, p. 148. analizando estas cuestiones:

El conflicto entre razón y tradición, entre el pensamiento racional y un pensamiento todavía inmerso en las creencias colectivas atávicas (logos vs. mitopoiesis) lejos está de poder ser reducido a un antagonismo entre Occidente y las otras civilizaciones. Tanto en India y China antiguas, como en la Persia sasánida y el Islam medieval, hallamos ejemplos notables de librepensamiento, de intelectuales nada occidentales que investigan y reflexionan dejando más o menos en suspenso las opiniones comúnmente aceptadas, los preceptos de la fe ortodoxa y las ideas consagradas por el poder estatal, es decir, racionalmente. En la India de los Mahajanapadas, las escuelas nastika se apartan de la revelación védica y desconocen la autoridad de los brahmanes. En China, durante el período de Otoño e Invierno y la época subsiguiente de los Reinos Combatientes, el mohismo cuestiona abiertamente al confucianismo, a la sazón, doctrina oficial. En la Persia sasánida, las academias de Nísibis y Gundishapur absorben y difunden el saber griego suscitando malestar en las filas del viejo clero zoroastriano; en el mundo árabe de la Edad de Oro, y de la mano de un sinnúmero de sabios prominentes (Al-Kindi, Al-Farabi, Avicena, Averroes, Ibn-Jaldún, etc.), la falsafa (ciencia y filosofía) se desarrolla con un vigor extraordinario para alarma e indignación de los sectores más conservadores, que pretendían reducir la actividad intelectual a la tradicional kalam (exégesis coránica y teología revelada). Si bien la filosofía y la ciencia árabes tienen —al igual que sus homólogas bizantinas y occidentales- un origen griego, el extraordinario desarrollo que aquellas alcanzaron demuestra que la racionalidad dista mucho de ser un rasgo exclusivo de la civilización occidental. ${ }^{14}$

\section{Genealogía}

Mignolo se ha preocupado por establecer una genealogía de pensadores decoloniales avant la letre, y de reivindicar como decoloniales ciertos proyectos políticos o intelectuales. $\mathrm{Ha}$ reivindicado como proyectos decoloniales al zapatismo y al MAS Boliviano, aunque ambas experiencias son profundamente diferentes y aunque, hasta donde sabemos, ni el zapatismo ni el MAS se han reconocido decoloniales. Las razones por las que el indianismo "capitalista andino-amazónico" que propugna el MAS sería decolonialmente reivindicable, pero no el indianismo anticapitalista de Felipe Quizpe, no son claras. Pero prefiero detenerme en la genealogía propuesta.

Una de las figuras reivindicadas es el historiador mexicano Edmundo O'Gorman, quien mostró historiográficamente cómo se construyó o inventó la idea de América. En opinión de Mignolo,

14 Federico Mare, texto enviado por mail al autor, 2019. 
"la tesis de O'Gorman se sitúa en la genealogía del pensamiento criollo decolonial". ${ }^{5}$ Ahora bien, quizá cause sorpresa saber que la cita del epígrafe con el que iniciamos este escrito (aquella que decía que la Civilización Occidental es la única vital) pertenece precisamente a O'Gorman, y se halla nada más y nada menos que en el prólogo a La invención de América (el libro que Mignolo reivindica como precursor del pensamiento decolonial)..$^{16}$ Por supuesto que la tesis de O'Gorman es potente $y$, hasta donde alcanza mi saber, correcta: América no fue descubierta, fue inventada. Pero a esta conclusión llegó utilizando criterios, métodos y conceptos que no difieren de los que podría haber empleado cualquier pensador europeo, y a pesar de un marcado occidentalismo. Desde luego la desgraciada y ostensiblemente falsa afirmación con la que finaliza su prólogo no debe impedirnos apreciar la potencia de sus tesis específicas. Pero si O'Gorman o su tesis pueden ser considerados decoloniales, la necesidad de un "desprendimiento" epistémico cae por tierra.

Waman Poma (o Guamán Poma, según elijamos la grafía quechua o castellana) sería a juicio de Mignolo el primer decolonial. En su opinión, para la teoría política del mundo colonial Waman sería tan importante como Maquiavelo para Europa. Sin embargo, la reivindicación decolonial de Waman es ciertamente problemática. El propio Mignolo relata una objeción que se le hizo a la misma, y luego elabora una justificación. El párrafo es un tanto extenso, pero creo que va al meollo del asunto y merece ser citado y discutido con cuidado. Escribe Mignolo:

La teoría política de Waman se articula en dos principios: primero, la crítica a todos los grupos humanos identificables en la Colonia, según las categorías clasificatorias del momento. Pero, ¿cuál es el criterio que emplea Waman para su crítica? El cristianismo. ¿Cómo?, preguntó un estudiante en una de mis clases sobre Waman Poma: ¿cómo puede ser este un pensamiento decolonial si abrazó el cristianismo? Sin embargo, así es. Reflexionemos. A finales del siglo XVI y principios del XVII no había Diderot, ni Rousseau, ni Kant, ni Spinoza, ni Marx, ni Freud. Es decir, la crítica secular ilustrada no existía todavía. Waman Poma asume la cristiandad histórica y éticamente, en la medida en que argumenta la cristiandad de los andinos antes de la llegada de los castellanos. Históricamente Waman Poma sería un mentiroso, puesto que no hay cristianismo antes de la llegada de los castellanos. Pero en un nivel lógico-epistémico, el cristianismo en Europa no sería sino la versión regional de ciertos principios que afectan a la conducta humana y que establecen criterios para la convivencia, para el "buen vivir". El argumento de Waman Poma debe leerse en este segundo nivel y no en el primero. La lectura del primer nivel es eurocéntrica y le otorga a la cristiandad occidental europea (la que se expande

15 W. Mignolo, La idea de América Latina, op. cit., p. 58.

16 Edmundo O' Gorman, La invención de América, México, Fondo de Cultura Económica, 1995 [1958], p. 12. hacia América) la posesión de principios universales bajo el nombre de cristianismo. "Cristianismo", en el argumento de Waman Poma, es equivalente a "democracia" en la pluma y la palabra de los zapatistas: la democracia no es propiedad privada del pensamiento y la teoría política de Occidente, sino un principio de convivencia, de buen vivir, que no tiene dueño. Waman Poma se apoderó de los principios cristianos a pesar de y en contra de los malos cristianos españoles, así como los zapatistas se apoderan de los principios democráticos a pesar de y en contra del gobierno mexicano en contubernio con la comercialización de la democracia en el mercado de Washington. ${ }^{17}$

¿Resulta convincente este alegato? Veamos. Para cualquiera que lea la obra de Waman Poma, es evidente que lo que se propone es algo así como un colonialismo mitigado. Una colonialidad algo más respetuosa de las diferencias. Esto por un lado. Pero, por otro, hay que decir que, contemporáneos a Waman, diferentes movimientos indígenas rechazaron de plano el cristianismo y se propusieron o soñaron la expulsión de los españoles. El movimiento Taki Onqoy, por ejemplo, instó a sus miembros a abandonar todo elemento hispano, desde la religión a la vestimenta, pasando por la lengua y la tecnología (¿no era esto un radical "desprendimiento"?), a la espera del regreso de las huacas que habrían de vencer a los dioses españoles y restablecer un nuevo orden andino de igualdad y bondad, tal y como creían fueron las cosas antes incluso del imperio incaico. ${ }^{18}$ Los líderes del estado neoinca, por su parte, aunque no rechazaban de plano todo lo que tuviera origen europeo (emplearon con bastante eficacia algunas de sus armas y tecnología), se proponían expulsar a los españoles (no convivir con ellos) y reconstruir el incanato. A ojos de unos y otros, alguien como Waman debería parecer algo así como un traidor o un colaboracionista. En cualquier caso, la opción de Waman no era ni fue la única posible en su momento histórico, para quien quisiera resistir la colonización.

El hecho de que entre 1594 y 1600 Waman se desempeñara como intérprete en las campañas contra las religiones andinas emprendidas por el visitador religioso Cristóbal de Albornoz, que su obra estuviera dirigida al rey de España y que justificara su utilidad diciendo que "la dicha corónica es muy útil y prouechosa y es buena para emienda de uida para los cristianos yenfieles y para confesarse los dichos indios y emienda de sus uidas y herronía, ydúlatras", no afectaría, según Mignolo, su contenido decolonial..$^{9}$ Más aún, a su juicio, "la 'nueva corónica' no es una

17 W. Mignolo, "El pensamiento decolonial: desprendimiento y apertura. Un manifiesto", en Santiago Castro-Gómez y Ramón Grosfoguel, El giro decolonial. Reflexiones para una diversidad epistémica más allá del capitalismo global, Bogotá, Siglo del Hombre Editores, 2007, pp. 36-37.

18 Sobre el movimiento Taky Onqoy y sobre el estado neoinca parece ineludible remitir a la obra ya clásica de Steve Stern, Los pueblos indígenas del Perú y el desafío de la conquista española, Madrid, Alianza, 1986.

19 Felipe Guamán Poma de Ayala, Nueva Corónica y buen gobierno, t.I, Caracas, Biblioteca Ayacucho, 1980, p. 4. 
corrección de errores españoles dentro de la misma lógica epistemológica hispánica (como en cierta manera lo son los 'comentarios' del Inca Garcilaso de la Vega)", y por ello, por ser crítico de los españoles, Waman habría entrado:

en una disyuntiva con las autoridades españolas y pagó el precio de ser pasado bajo silencio durante cuatro siglos. Inca Gracilazo [sic] de la Vega, en cambio, gozó rápidamente de la fama porque se queda dentro del sistema. ${ }^{20}$

Anotemos que por muy crítico que fuera Waman, y por muy conciliador que fuera Garcilaso, ello no demostraría que producían necesariamente dentro de diferentes lógicas epistémicas: habría que demostrarlo. Pero además los hechos históricos pertinentes son ambiguos. Es cierto que Garcilaso tuvo gran fama en vida, pero su obra maestra Comentarios reales sobre los incas, publicada en Lisboa en 1609, fue prohibida por la Corona Española en las colonias americanas luego del levantamiento de Tupac Amaru II. Las razones por las que la obra de Waman Poma no llegó a su destinatario no son nada claras; pero no parece que fuera sencillo que le llegara al Rey un manuscrito enviado por un desconocido, fuera cual fuese su contenido. En cualquier caso, la afirmación de que Waman no operaría dentro de la lógica epistemológica hispánica (mientras que Garcilaso sí) requeriría una justificación que Mignolo no proporciona ni intenta proporcionar.

Ahora bien, para defender su posición Mignolo introduce un elemento que, bien considerado, socava en realidad los pilares de todo el andamiaje decolonial en tanto que propuesta de desprendimiento radical. Se trata de lo siguiente. Según Mignolo: "cristianismo" para Waman, como "democracia" para los zapatistas, no son propiedad privada de Occidente, sino principios de convivencia, principios de "buen vivir", que no tienen dueño. $Y$ efectivamente podemos aceptar que es así. Pero lo mismo se aplica a cualquier principio: monarquía, teocracia, castas, islam, socialismo, ciencia, razón, totalidad, relativismo, etc. Ninguno es propiedad privada ni de Occidente ni de Oriente. Sin importar dónde se haya iniciado ni dónde ni cuándo se haya desarrollado, cualquier cultura o grupo puede hacer libre uso de los mismos. Pero una vez que se acepta esta premisa, resulta imposible aceptar o rechazar un principio porque forma o no forma parte de mi tradición (criterio conservador por antonomasia); y a todos los principios se les debe aplicar la misma vara: no se los acepta o rechaza por su origen o procedencia, sino por las razones sustantivas que podemos tener en favor o en contra de su veracidad/falsedad, bondad/maldad, utilidad/inutilidad, justicia/injusticia, etc. No hay dudas de que el cristianismo y la democracia realmente existentes han servido para oprimir y explotar gente. Habría ciertamente muy buenas razones para rechazarlos. Pero también se pueden esgrimir muy buenas razones para abrazar sus principios. $Y$ que se haya hecho un uso

20 W. Mignolo, Desobediencia epistémica, op. cit., p. 40. éticamente deplorable de los mismos no significa que sea esa la consecuencia ineludible del cristianismo o la democracia como principios abstractos. Lo mismo vale para la ciencia, el marxismo, el islam, la idea de totalidad o lo que se quiera. Lo que se impone es un cuidadoso examen de múltiples niveles. Una indagación detallada y meticulosa. Justamente lo que nunca se encuentra en los escritos decoloniales.

Puede ser que para Waman el cristianismo fuera un simple criterio de convivencia, y que para los zapatistas lo sea la democracia. Pero no pensaban como Waman los takiongos ni piensan como los zapatistas, por ejemplo, los dirigentes mapuche que reivindican formas tradicionales de liderazgo (algunas hereditarias) y ven en la democracia una pura forma wingka. Me consta que para algunos activistas mapuche decir que el cristianismo y la democracia son "meras formas de convivencia que no tienen dueño" no es más que reproducir la cosmovisión occidental. ${ }^{21}$

En relación a Waman Poma escribe Mignolo en el mismo texto:

Guamán Poma en una movida sorprendentemente genial, asume la cristiandad de los Indios y, al hacerlo, rechaza la conversión. En ese gesto se desprende de Las Casas, cuya crítica a los castellanos, Guamán Poma endosa. Pero que no le vengan a convertir a la cristiandad puesto que los habitantes de Tawantinsuyu son ya cristianos. El desprendimiento por tanto no significa negar e ignorar lo que no se puede negar, sino de saber como utilizar técnicas o estrategias imperiales con propósitos descoloniales. ${ }^{22}$

El problema, claro, es quién determina qué se puede negar y qué no. Podemos simpatizar más o menos con los caminos elegidos por los takiongos, por Waman o por los neoincas (todos igualmente fracasados en sus objetivos explícitos), pero la existencia de tales caminos muestra a las claras lo ambiguo y complejo que resulta aquello de que el desprendimiento "no significa negar e ignorar lo que no se puede negar, sino de saber como utilizar técnicas o estrategias imperiales con propósitos descoloniales". Porque exceptuando la aceptación del asimilacionismo más absoluto, cualquier creencia o acción de una etnia oprimida podría ser considerada decolonial en nombre de comprender que ciertas cosas ya no pueden ser negadas (el "marranismo" sería un claro ejemplo histórico). Y convendría aclarar que no estoy rechazando ciertas evidencias, en un plano puramente empírico sería necio negarlas. Pero los proyectos sociales, culturales y políticos no se sustentan únicamente en evidencias sobre lo que

21 Cuando le señalé a un militante mapuche tradicionalista que la democracia no es un principio exclusivo de "Occidente", sino algo reivindicado, por ejemplo, por los zapatistas mayas, me retrucó que eso era así porque los mayas habían sido conquistados en el siglo $\mathrm{XVI}$, en cambio los mapuche, "que resistimos hasta fines del siglo XIX, estamos mucho menos colonizados".

22 W. Mignolo, Desobediencia epistémica, op. cit., p. 39. 
hay. Se sustentan también en principios o valores (que pueden ser discutidos, pero casi nunca refutados como se refutan datos empíricos), y en expectativas de futuro que pueden parecernos más o menos realistas, pero sobre las que no se puede tener el mismo grado de certeza que sobre los hechos ya ocurridos. En cualquier caso, la opción decolonial oscila entre un llamado a un desprendimiento radical de la episteme eurocentrada y un mucho más moderado llamado a buscar diferentes formas de combatir las opresiones étnicas. Sin embargo, parece ser que estas dos caras poseen una diferente orientación temporal. Hacia el pasado se adopta la variante moderada: cualquier forma de resistencia es considerada decolonial en pos de construir una genealogía. En el presente, en cambio, se adopta la versión radical con miras a trazar claras delimitaciones con otras corrientes o tradiciones emancipatorias. Las razones de esta diferencia son políticas antes que teóricas.

En su genealogía decolonial Mignolo sostiene:

La descolonialidad fue claramente formulada en los años sesenta y setenta por los pensadores arabo-islámicos (Sayyid Qutb, Ali Shariati, Ayatollah Komeini); por pensadores afrocaribeños (Aimé Césaire, Frantz Fanon) por la filosofía de la liberación en América Latina y por intelectuales indígenas y activistas en América Latina, Australia, Nueva Zelanda y Canadá. ${ }^{23}$

Qué sería lo uniformemente decolonial en los autores que Mignolo incluye en su genealogía no queda nada claro (al margen de ser miembros de etnias oprimidas o de países periféricos que desarrollan alguna crítica al colonialismo): sus análisis son muy diversos y sus propuestas mucho más aún. Pero aquí opera el criterio de apropiación del pasado en pos de construir una (mitológica) genealogía. Amartya Sen y Kwame Anthony Appiah, en cambio, reproducirían, según Mignolo, el pensamiento eurocentrado. Aquí opera la necesidad de diferenciarse de autores contemporáneos o corrientes teóricas con presencia académica, críticos del colonialismo y la opresión/discriminación étnicoracial para erigir una opción teórica diferente: la decolonial. La frontera entre quienes son y quienes no son considerados genuinamente decoloniales carece de fundamento teórico. $Y$ aunque se halla políticamente motivada carece también de claro fundamento político. Más bien, al menos en el caso de Mignolo, quiénes son considerados decoloniales y quiénes no depende de su libre arbitrio.

\section{Decolonialidad a ras del suelo}

Traduzcamos la propuesta decolonial a términos concretos y

23 W. Mignolo, Desobediencia epistémica, op. cit., p. 26. actuales. Vivo en wallmapu y, al interior del pueblo mapuche tanto al este como al oeste de la Cordillera de los Andes, se desarrollan diferentes perspectivas que atañen desde la definición de quién es mapuche hasta cuestiones tácticas, pasando por diferentes objetivos político-culturales a largo plazo. ${ }^{24}$ Algunos intelectuales y activistas mapuche, apelando entre otros argumentos a un dato que no se puede negar -a saber, que al día de hoy la mayor parte de las personas que se reivindican mapuche vive en contextos urbanos, sin constituir una mayoría de la población en ninguna región-, han desarrollado propuestas en el camino de conseguir autonomía regional en las regiones de Chile en las que viven los más numerosos contingentes de mapuche, pero concibiendo la autonomía tanto para mapuche como chilenos desde una perspectiva intercultural. En esta senda han priorizado la acción política (por sobre la etno-gremial) y algunos han creado un partido político mapuche: Wallmapuwen. Pero no todos están de acuerdo. Hay quienes piensan que los que viven en ciudades no son verdaderos mapuche o totalmente mapuche, y por eso se concentran en reivindicaciones de corte más bien económico para los campesino-mapuche, y ven en el ingreso a la arena política una vía para que algunos mapuche mejoren su posición, sin modificar realmente la situación de la mayoría. ${ }^{25}$ Otros piensan que la lucha etno-gremial de los campesinos mapuche es insuficiente, pero que es inviable o ilusorio construir un partido mapuche: lo inteligente es usar los espacios de los partidos chilenos en beneficio de los mapuche (y hay un amplio abanico de opciones en relación a cuál partido sería el indicado). Otros creen que los mapuche deben regresar

24 En mi condición de katripache (no mapuche que apoya las demandas mapuche) he acompañado numerosas actividades (como movilizaciones o conferencias de prensa), me he pronunciado en favor de que Argentina se convierta en un estado plurinacional (una posición que hoy no sostiene ninguna fuerza con representación parlamentaria) y he formulado por escrito críticas al pensamiento argentino colonial. Ver por ejemplo Ariel Petruccelli, Pablo Scatizza y Mauricio Suraci, "Roca, su monumento y las barbaries de Romero", Viento del Sur, 2012, disponible en http:// www.revistavientodelsur.com.ar/roca-su-monumento-y-las-barbariesde-romero; Ariel Petruccelli y Pablo Scatizza, "Una posición frente a la resistencia a izar el wenufoye en San Martín de los Andes", Izquierda Diario, 2014, disponible en https://www.laizquierdadiario.com/Unaposicion-frente-a-la-resistencia-por-izar-el-wenufoye-en-la-PlazaSan-Martin; Ariel Petruccelli, "Los mapuche y un discurso de terror", Izquierda Diario, 2017, disponible en https://aizquierdadiario.com/ Los-mapuche-y-un-discurso-de-terror, Andrea Barriga y Ariel Petruccelli, "Santiago Maldonado: crónica de una desaparición forzada", Sin Permiso, 2017, disponible en http://www.sinpermiso.info/textos/santiagomaldonado-cronica-de-una-desaparicion-forzada; Andrea Barriga y Ariel Petruccelli, "Santiago Maldonado: entre la montaña de mentiras y la larga marcha hacia la verdad", Sin Permiso, 2017, disponible en http:// www.sinpermiso.info/textos/santiago-maldonado-entre-la-montana-dementiras-y-la-larga-marcha-hacia-la-verdad-en-la-argentina.

25 Contra la esencialización campesina de los mapuche, Marimán nos recuerda que "la construcción de lo mapuche como campesino en reducciones y después en comunidades es ahistórica, porque el resultado de la incorporación forzada y la expoliación territorial con la creación de reducciones de tierra, produjo a su vez la diáspora mapuche a las ciudades y la emergencia del mapuche urbano. De manera que mapuche campesino-intensivo y mapuche urbano son el resultado del mismo proceso". José Marimán, Awkan tañi müleam Mapu kimün. Mañke ñi pu Kintun, Santiago de Chile, Centro de Estudios RümtunFundación Heinrich Böll Cono Sur, 2017, p. 12. 
a la pureza de su cultura, aislándose todo lo posible de las sociedades chilena y argentina para desarrollar su propia lengua, su propia cosmovisión, su propia epistemología, etc. -e incluso identidades más específicas (nagche, wenteche, lafkenche) con demandas exclusivistas para las mismas, que a ojos de otras corrientes de opinión fragmentan al movimiento y favorecen a los colonizadores, maestros en el uso del "divide y vencerás"-. No he agotado el espectro de las posiciones políticas mapuche, pero es suficiente para dar una idea de su diversidad.

Pues bien: ¿cuál de todas estas opciones sería decolonial? Si nos tomamos en serio aquello de que sería válido "utilizar técnicas - estrategias imperiales con propósitos descoloniales" habría que concluir que todas lo son. Si esto es correcto, entonces la conclusión que se impone es que la decolonialidad puede ser cualquier cosa más allá de la asimilación auténtica: incluso la asimilación fingida (como aquellos grupos que fingen hacia el mundo exterior ser como el resto, aunque a su interior y en su conciencia se siguen considerando diferentes) podría ser considerada decolonial. Sin embargo, Mignolo sostiene que la decolonialidad implica romper con los marcos epistémicos occidentales, practicar un "desprendimiento". Tanto es así que incluso los primeros proyectos de "desconexión" (como el de Samir Amin) le parecen insuficientemente decoloniales. ${ }^{26}$

No está claro cómo encajaría la demanda decolonial de "desconexión" con la aceptación del cristianismo y la democracia. Pero si llevamos la propuesta de Mignolo al campo de las actuales discusiones entre los mapuche, resulta claro que su perspectiva empalma con los discursos más etnicistas y tradicionalistas, los menos interculturales, los más proclives a buscar la autonomía por medio de una estricta separación de la sociedad chilena (o argentina) y el refugio en pequeñas comunidades mapuche "puras" (que hoy representan una ínfima proporción de quienes se consideran mapuche). Es entre esta franja del pensamiento mapuche, de hecho, en la que se reclama romper con la racionalidad occidental, se ve como prioritario recomponer la cosmovisión mapuche y se desconfía de los principios democráticos. No es ésta la ocasión para ponderar fortalezas y debilidades de las diferentes propuestas mapuche. Pero parece evidente que una perspectiva como la de José Marimán (quien, además de académico, ha sido un activista del autonomismo mapuche, en su caso desde una perspectiva etno-nacionalista intercultural) debería ser considerada como todavía colonizada, dado que se halla muy lejos de querer romper con la supuesta "racionalidad occidental" (Marimán seguramente discutiría

26 Según Mignolo, "Amin se mantuvo en la burbuja de la episteme moderna, y su de-linking sugirió un cambio de contenido, no de los términos de la conversación". W. Mignolo, "El pensamiento decolonial: desprendimiento y apertura. Un manifiesto", op. cit., p. 29, nota a pie. Obsérvese que Amin estaba vivo cuando estas líneas fueron escritas: había que diferenciar al proyecto decolonial del de Amin, demasiado marxista. Y no está mal trazar diferencias, lo que parece intelectualmente injustificable es trazarlas sin mayor argumentación. que tal cosa exista). Marimán sostiene imperturbablemente un pensamiento genuinamente crítico y, en tanto tal, también autocrítico. Ha escrito por ejemplo:

después de 476 años de contacto con el occidente colonialista y particularmente después de 129 años de vivir bajo dominación estatonacional chilena [y argentina, podríamos agregar, AP], resulta pertinente preguntarse, ¿tienen los mapuche en el presente una cosmovisión diferente? (más bien parece que al interior de los mapuche pululan varias cosmovisiones, siendo la que podríamos -no sin discusiónllamar "mapuche" la que menos al parecer adeptos tiene). Y, ¿tuvieron los mapuche una tradición política e institucional que por lo demás sea digna de copiar (esto es democrática, respetuosa de los derechos humanos, etc., de acuerdo con los estándares presentes)? Hasta ahora el tradicionalismo mapuche se ha mostrado productivo levantando mitos sobre una institucionalidad propia superior a la occidental y la idea del indio ecológico viviendo en armonía con la naturaleza, pero estas son cuestiones que, más allá del mito hay que demostrar. Esto es, hay que probar que existieron, que son mejores a las "chileno occidentales", y que son funcionales en el presente, promoviendo la participación de todos los mapuche y no sólo de unos jefes por nacimiento u otras

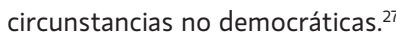

Quizá al interior del mundo académico retóricas como la de Mignolo sirvan para abrir las perspectivas, incorporar otras voces, dotar de legitimidad epistémica a sujetos que no son reconocidos. Pero en el caso de los mapuche este tipo de retóricas fortalecen el aislacionismo, el refugiarse en la microcomunidad y las pichi identidades y la aceptación de prácticas culturales con la única legitimidad de ser supuestamente ancestrales -legitimación conservadora por excelencia-. Más que un diálogo intercultural, dicha retórica apuntala una perspectiva etnocéntrica, comprensible, y en parte justificable, en tanto etnocentrismo del oprimido; pero a mi juicio inaceptable como perspectiva genuina de liberación.

\section{La decolonialidad como teoría y como práctica}

Pero una propuesta teórica no puede ser evaluada por las consecuencias que produce (porque puede producir diferentes consecuencias en distintos lugares y circunstancias). Es indispensable, pues, evaluar sus propuestas sustantivas, con relativa independencia de los usos que se hagan o puedan hacer de ellas. Y aquí es donde se busca y se busca en vano. Ninguno de todos los enormes temas y problemas abordados por quienes se autodenominan decoloniales se desarrolla por medio de

27 José Marimán, Autodeterminación. Ideas políticas mapuche en el albor del siglo XXI, Santiago de Chile, LOM, 2012, p. 298. 
una discusión pormenorizada con autores contemporáneos específicos. De hecho, sus críticas se dirigen a abstracciones nunca bien precisadas, como los marcos epistémicos, la retórica de la modernidad, la hybris del punto cero, la teo-logía y la egología; y se caracterizan por afirmaciones tajantes y genéricas, antes que por la discusión paciente de tesis específicas hechas por autores o autoras específicos. Y esto a pesar del prolongado lapso temporal transcurrido desde que la opción decolonial se dio a conocer públicamente. ¿Para qué perder tiempo en esas minucias? Hay que ir derecho al hueso y demoler los cimientos teo-lógicos y ego-lógicos del marco epistémico occidental: esa parece ser la perspectiva. El problema es que los cimientos supuestamente demolidos no son más que una caricatura.

¿Cuál es exactamente la definición, los limites y las características de la "episteme eurocentrada" objeto de crítica? La respuesta es un ejercicio conceptual que no he sido capaz de hallar en la abundante literatura decolonial que he leído (y la vengo leyendo desde 2006). Dado que se trata de una idea central, no parece probable que sea un descuido o que se halle oculta en algún texto arcano. Sucede que la perspectiva decolonial reproduce consciente o inconscientemente los motivos del panideologismo romántico: reducción de toda labor intelectual a una sustancia común -esencialmente ideológica-, negativa a precisar o definir los conceptos y dificultades para reconocer lo que las actividades cognitivas tienen de conocimiento como tal (en favor de sus implicancias ideológicas reales o supuestas). Lukács, para citar a un autor de mi propia tradición marcado por esta concepción del quehacer intelectual, pudo escribir cientos de páginas criticando al irracionalismo sin proporcionar siquiera una elemental definición de qué entendía por razón. ${ }^{28}$ Los pensadores y pensadoras decoloniales pueden dedicar libros enteros a destruir una episteme que nunca han definido, pero en cuya bolsa se puede poner a cualquier pensador o pensadora de origen europeo, sin importar cuán diferentes sean: serán considerados diferentes dentro de lo mismo. Y punto.

El pensamiento decolonial insiste tanto en la crítica al pensamiento y las prácticas filosóficas y científicas como en la reivindicación de "saberes otros". Pero es evidente que la tradición europea tiene una larga historia de pensamiento y de prácticas religiosas, estéticas, mágicas, míticas y chamánicas (tan eurocentradas, para el caso, como las científicas o filosóficas). Ciencia y chamanismo pueden ser parte de una misma tradición cultural en sentido amplio, pero claramente no son parte de una misma tradición intelectual (la decolonial noción de episteme oscila imprecisa y eclécticamente entre uno y otro polo). Uno de los mayores riesgos de la opción decolonial reside en el tendencial rechazo a los que quizás sean los mejores frutos intelectuales de cierta tradición cultural (como la ciencia o la filosofía crítica),

28 Al respecto ver el magnífico trabajo de Manuel Sacristán, "Sobre el uso de las nociones de razón e irracionalismo por G. Lukács", Sobre Marx y marxismo, Barcelona, Icaria, 1983. para abrazar acríticamente frutos menos nutritivos (como la magia o la religión), por creer equivocadamente que ellos son auténticos "pensamientos otros", como si carecieran de anclaje en la tradición cultural del colonizador o fueran incompatibles con la dominación.

Antes que pensamiento crítico, la decolonialidad se nos presenta como un nuevo dogmatismo, plagado de tajantes afirmaciones nunca justificadas, contradicciones manifiestas, uso y abuso de la falacia de la descalificación ad hominem, críticas genéricas en lugar de discusiones detalladas, énfasis en diferenciar su concepción de otras corrientes emancipatorias (antes que tender puentes con las mismas), proliferación de nociones "novedosas" que rara vez se convierten en conceptos precisos (condición indispensable para evaluar su pertinencia teórica), "apropiación" sin reconocimiento de las ideas de otros, etc. Puede que estas palabras suenen un tanto duras. Pero en ocasiones no es ni posible ni deseable decir las cosas a medias. En cualquier caso, incluso al interior de la red modernidad/colonialidad se han formulado acusaciones en el mismo sentido y del mismo tenor, y empleando un lenguaje tanto o más severo. Ramón Grosfoguel, por ejemplo, ha dicho en una entrevista que "Mignolo dice una cosa un día y dice otra cosa al otro, depende con quién esté hablando. No es consistente ni tiene coherencia teórica" ${ }^{29} \mathrm{Y}$ no empleó un lenguaje mucho más amable con Aníbal Quijano:

El concepto de capitalismo racial de Robinson contiene ya la idea que Quijano expresa con el término colonialidad unos 20 años antes que él. Además, también hay pensadores indígenas que han observado este vínculo. ¿Por qué Quijano nunca los cita?, ¿por qué nunca cita a una pensadora negra o a un pensador crítico del islam o de otras coordenadas? Para mí esto es problemático, porque si estamos produciendo un pensamiento decolonial no podemos reproducir el universalismo, donde uno define para todos. ¡Ahora resulta que Quijano es el principio y el fin del tema de la colonialidad! Quijano es un pensador que bebió de todas esas fuentes. Que no las quiera reconocer es otro problema. Yo no me identifico con esa tendencia de no reconocer el pensamiento indígena y negro. Ese pensamiento precede a Quijano y ha sido tan radical como lo que produjo Quijano en los años noventa del siglo pasado. Quijano bebió también de Mariátegui, pero si observas sus trabajos que hizo sobre Mariátegui en los setenta y ochenta enfatiza que Mariátegui es un pensador del sistema capitalista mundial pero no habla tanto de sus aportaciones al tema del racismo. Quijano nunca aborda la cuestión de la raza como un principio organizador de la economía política hasta que acuña el término de la "colonialidad" en los años noventa. ${ }^{30}$

29 R. Grosfoguel, "Entrevista a Ramón Grosfoguel. Por Luis Martínez Andrade", Analéctica, Año $0, n^{\circ} 1,2013$, p. 5.

30 Ibíd, pp. 10-11. 
Para rematar, Grosfoguel concluye:

Lo patético es ver cómo el autor de la "colonialidad del poder" tiene una epistemología colonial que no reconoce a ninguna pensadora o pensador del sur global ni reconoce la tradición crítica anterior que analizó las cuestiones que Quijano nombra con la palabra "colonialidad" pero que usaron términos conceptuales diferentes para nombrar lo mismo. La epistemología colonial de Quijano reproduce el monólogo solipsista y autorreferenciado cartesiano. ${ }^{31}$

La crítica de Grosfoguel apunta a lo que podríamos considerar contradicciones performativas: el abismo entre lo que se dice y lo que se hace. Pero asume sin más las premisas teóricas desarrolladas dentro de la red modernidad/colonialidad, y ello lo lleva a sostener dudosas generalizaciones o formular afirmaciones tan arbitrarias como que "el concepto de novedad es totalmente moderno y colonial". 32 Y también lo lleva a achacar todos los males a una episteme "occidental" no sólo esencializada, sino también concebida como dominando incluso a quienes se consideran y declaran sus opositores radicales. Con tal perspectiva simplifica y uniformiza en exceso a los pensamientos desarrollados en "Europa". Además se muestra incapaz de reconocer la autonomía y especificidad de algunas formas de pensamiento desarrolladas fuera del mundo euronorteamericano (y en lucha con él), las cuales a sus ojos no serían más que formas invertidas de eurocentrismo. Así por ejemplo ha podido declarar:

Entonces, lo que hace el "fundamentalismo-tercermundista" es invertir estas categorías y aceptar la premisa del "fundamentalismo eurocéntrico" y decir: es verdad la democracia es occidental, no se aplica a mí, yo defiendo la monarquía (eso es Ben-Laden); la igualdad no me pertenece a mi, así que yo apoyo la desigualdad; los derechos de la mujer son occidentales, aquí tenemos a la mujer que debe obedecer al hombre, etc. Este tipo de reflexiones, no son sino una caricatura del otro invertida y asumiéndose como superior: agarra las mismas premisas del discurso eurocéntrico, las invierte, las deja intactas, y afirma su otredad como superior a la de occidente. Eso es, fundamentalismo hoy en día, y eso no es otra cosa que fundamentalismo eurocentrista invertido, es decir, diversas visiones del mismo problema eurocéntrico. Para mí Ben-Laden, es tan fundamentalista eurocéntrico como Habermas, porque están atrapados en las mismas premisas del pensamiento occidental. ${ }^{33}$

Como es obvio, ni la democracia ni la monarquía son conceptos

31 Ibíd, p. 12.

32 "Entrevista a Ramón Grosfoguel. Por Angélica Montes Montoya y Hugo Busso", Polis. Revista Latinoamericana, n. ${ }^{\circ} 18,2007$, p. 30.

33 Ibíd, p. 26. pura y exclusivamente europeos (ni de ninguna otra etnia particular). Si fuera cierto que Ben Laden pensaba que la democracia es europea y la monarquía no, es obvio que se equivocaba: las monarquías han dominado en Europa por mucho más tiempo que las democracias, y todavía subsisten monarquías europeas. No existe algo así como "premisas del pensamiento occidental" (u oriental): hay muchas premisas, muy diferentes y fuertemente contradictorias entre sí desarrolladas al interior de cada tradición cultural; y las tradiciones culturales han estado mezclándose a lo largo de milenios. Grosfoguel señala con justicia que Mignolo culmina atribuyendo la pertenencia epistémica por medio de un burdo criterio geográfico, confundiendo localización social con localización epistémica. Pero sucede que una vez que se asume la existencia de marcos epistémicos atribuibles intrínsecamente a un grupo étnico o definibles fundamentalmente por su carácter étnico, no quedan muchos otros caminos que el reduccionismo geográfico/etnicista de Mignolo o la inconsistencia: esto es, reclamar la existencia de epistemes intrínsecamente propias de un grupo étnico, pero reconocer que las mismas pueden ser asumidas por otros grupos (lo que desmiente su carácter intrínseco), tal como hace Grosfoguel al considerar que Ben Laden es tan eurocéntrico como Habermas. ${ }^{34}$ La salida a este engorro consiste en evaluar las teorías y doctrinas en sus propios términos -sin definirlas en términos sociales o geográficos ni, mucho menos, invalidarlas o aceptarlas por el origen social de sus defensores o defensoraspero sumando, como una dimensión analítica entre otras, los eventuales vínculos que una teoría pudiera tener con un grupo social o los usos políticos posibles de la misma. Esto es lo que buena parte del pensamiento crítico ha venido haciendo desde hace decenios a lo largo del mundo entero. ${ }^{35}$ En este terreno, las propuestas decoloniales, en lugar de sumar claridad, han sumado confusión.

Quizá entre las nuevas generaciones de intelectuales que asumen

34 Por lo demás, si tanto Habermas como Ben Laden pueden ser considerados eurocéntricos, parece evidente que la noción de eurocentrismo en cuestión es virtualmente vacía. Un significante flotante, antes que un concepto mínimamente preciso.

35 Es sabido que el dogmatismo marxista creía poder desechar teorías enteras por el origen de clase de sus autores, o por los usos políticos que se les diera en un momento determinado. La aberrante idea de una "ciencia proletaria" causó infinitos males en su momento. Pero parece que hay lecciones que cuesta aprender. La opción decolonial tiende a reproducir la misma concepción falaz, aunque ahora no en términos clasistas, sino etnicistas o geográficos (como la "epistemlogía del sur" de Boaventura de Sousa Santos). Algunas corrientes feministas la reproducen en términos de género. Así como los marxistas críticos lucharon en su momento contra los absurdos de la "ciencia proletaria", hoy -quienes tengamos simpatías por los pueblos colonizados y por las demandas feministas- debemos luchar contra los absurdos (no por más nuevos menos graves) de las epistemologías étnicas o feministas. Esto no implica negar la existencia de sesgos de clase, étnicos o de género en la producción científica, pero de allí a postular y defender las propuestas de epistemologías de clase, de género o étnicas hay un abismo: el que separa a la ciencia (con su anhelo nunca del todo consumable de objetividad y universalismo) de la ideología (alegremente subjetivista y patrióticamente particularizadora). 
la opción decolonial el costado crítico se desarrolle a expensas del dogmático (como la tradición marxista pudo desarrollar un sólido pensamiento crítico en lugar de exaltados dogmas, a pesar de las no pocas tendencias a esto último). Pero en las dos primeras generaciones predomina una dogmática ingenua, y las propias bases del pensamiento decolonial (afirmado en la indistinción de niveles analíticos y operaciones intelectuales, así como en la implícita y a veces explícita desconfianza a la lógica y la epistemología) hacen muy dificultosa la criticidad, cuyo fundamento son necesariamente las sutiles diferenciaciones, el máximo rigor lógico y exigentes criterios de evidencia empírica. La criticidad, en este sentido, no tiene vinculaciones apriorísticas en términos políticos o ideológicos: se puede ser crítico de derechas y dogmático de izquierdas, y viceversa. Es claro, por lo demás, que nadie es absolutamente crítico o absolutamente dogmático; pero se puede ser mucho más una cosa que la otra.

Aunque las propiedades específicas y los límites concretos de cada marco epistémico nunca son establecidos en los escritos decoloniales, no hay dudas de que tales marcos son concebidos por Mignolo, de Sousa Santos, Grosfoguel o Quijano como unidades cerradas, de manera semejante a como Kuhn concebía los paradigmas científicos. Kuhn consideraba que los paradigmas científicos (a diferencia de las teorías al interior de un mismo paradigma) son inconmensurables, entre otras razones debido a que emplean lenguajes diferentes. A partir de esto (no sin ambivalencia, por cierto) llegó a concebir las revoluciones científicas como una suerte de "conversión", más semejante a las conversiones religiosas que al relativamente tranquilo proceso de deliberación racional en el que se desenvuelve la ciencia "normal" en los momentos de desarrollo no crítico (en los que la disputa se da entre distintas teorías pertenecientes a un mismo paradigma, y no entre paradigmas diferentes). Sin embargo, luego de las críticas que recibió, Kuhn moderó mucho su planteamiento inicial, que lo llevaba a una posición cuasi-irracionalista: de la inconmensurabilidad general pasó a la inconmensurabilidad local o parcial; y de la ausencia de criterios racionales para elegir entre un paradigma y otro, a defender que existían cinco vías para evaluarlos, aunque insistiendo en que estas vías eran menos concluyentes al evaluar paradigmas entre sí que al evaluar teorías dentro de un mismo paradigma (cosa obviamente muy sensata). Por lo demás, el ámbito tratado por Kuhn era relativamente acotado: no trataba de marcos epistémicos genéricos, inevitablemente imprecisos, sino de los marcos de problemáticas o disciplinas específicas (como la física), bien acotados y delimitados. $Y$ en el caso de las ciencias sociales Kuhn pensaba que eran pre o no-paradigmáticas: a su juicio no existe en ellas consenso como para hablar de un paradigma común. ${ }^{36}$ Ahora bien, en los escritos decoloniales típicos (quizá haya alguna excepción, pero no la he hallado) se

36 Un excelente tratamiento de la obra de Thomas Kuhn y de las polémicas por ella generada se encuentra en W. H. Newton-Smith, La racionalidad de la ciencia, Barcelona, Paidós,1987. asume una concepción cerrada de los paradigmas en una variante más próxima a la primitiva formulación kuhniana que a sus más cautas formulaciones ulteriores, y se lo traslada -de las muy precisas y acotadas problemáticas de disciplinas tales como la física- a todo tipo de conocimiento. Adicionalmente, se pretende que existen marcos epistémicos claramente diferenciables entre sí, cada uno de los cuales actuaría como una fuerza orientadora subyacente no sólo a las ciencias sociales, sino a todas las ciencias, la religión, el sentido común, los saberes políticos y cualquier dimensión cognitiva de cualquier práctica social. Las epistemes como Dios- estarían en todos lados y todo lo controlarían. Si tal cosa existe, pues habría que demostrarlo. No hay nada de malo en las generalizaciones en sí. Pero la generalización decolonial que pretende ver un patrón común en todas y cada una de las doctrinas, teorías y filosofías europeas es claramente abusiva, al menos para cualquiera que tenga algún grado de familiaridad con la formalización teórica, e incluso con la cautela intelectual.

Quizá la raíz de todos nuestros males esté en el "marco epistémico occidental" y en la "retórica de la modernidad". Pero, ¿qué es tal cosa? Desgraciadamente, como ya expuse, en la extensa literatura decolonial no he podido hallar ninguna especificación, ninguna conceptualización detallada. Tan sólo una serie de nociones vagas cuyo atractivo es retórico más que teórico. Lo que en ella se encuentra son ultrageneralizaciones, al estilo de la siguiente:

Resulta obvio que el desprendimiento no puede realizarse dentro del marco de las políticas teo- y ego-lógicas del conocimiento y del entendimiento. Spinoza o San Pablo no nos ayudan a desprendernos puesto que ellos son parte de la epistemología de la cual la descolonización epistémica busca desentenderse, desengancharse, quebrar el espejismo del pensamiento único y variado dentro de lo mismo. En efecto, ¿Cómo podría uno hacer el ejercicio de desprenderse dentro del marco epistémico del cual uno se quiere desprender? ${ }^{37}$

Dos mil quinientos años de reflexión intelectual parece que pueden ser reducidos a dos megaelementos -la teo-logía (centrarse en Dios) y la ego-logía (centrarse en el yo individual)_ y un único marco epistémico. La Ilustración no sería más que una variante del mismo viejo combo intelectual, no una ruptura con el mismo como se cree usualmente. El filosofar griego ( $\tan$ diferente a la teología medieval o moderna) entra en el mismo paquete, al igual que Derrida, Foucault, Freud e incluso Samir Amin, a pesar de que sus enfoques poco tienen que ver con el sujeto cartesiano que se supone fundaría la ego-logía. De ser cierto lo que dice Mignolo, habría que avisarles a los musulmanes y a los induístas (como mínimo) que si quieren salir de la situación de colonialidad, tienen que desprenderse de sus marcos epistémicos tan marcadamente teo-lógicos.

37 W. Mignolo, Desobediencia epistémica, op. cit., p. 40. 
La propuesta decolonial de "desprendimiento" se parece mucho a un pedido de conversión. Reproduce de manera invertida la perspectiva de los evangelizadores del siglo XVl: si para éstos los "indios" debían dejar de ser "indios" para ser plenamente humanos en la tierra y para conseguir la salvación en el cielo, para Mignolo al menos no hay salvación ni posibilidad de respeto intercultural si no nos desoccidentalizamos de manera integral. Desde luego, se puede retrucar, como lo hiciera Mignolo, que la decolonialidad se asume a sí misma como una opción entre otras, que sólo reclama el derecho epistémico a tener una "perspectiva otra" (al pensamiento único dominante), y su derecho a aliarse "con las propuestas de Pacari, Patzi Paco o Williams, y no con las de Blackburn o Bourdieu". ${ }^{38}$ Puesto así, parece un reclamo pluralista de amplitud conceptual y respeto intelectual. Sin embargo, no resulta muy pluralista un planteo que acepta que la perspectiva suya no es la única válida pero, al mismo tiempo, sostiene que sin el desprendimiento tal y como se lo entiende (cosa que por lo demás no queda nunca del todo clara) se reproduce la colonialidad. Esto sería como decir que el marxismo se asume como una más entre muchas opciones teóricas válidas, pero todas las restantes permanecen presas de la alienación. O que el cristianismo es una más entre muchas religiones legítimas, pero los creyentes de otras están condenados al infierno. Una auténtica actitud pluralista consiste en sostener que uno tiene buenas razones para defender sus opciones políticas y teóricas, pero aceptando que hay buenas razones para hacer otras elecciones, incluso persiguiendo las mismas finalidades. Y las razones no son buenas si esas perspectivas nos atan a la colonialidad, nos anclan en la alienación o nos condenan para toda la eternidad. Pero por sobre todas las cosas, un planteo pluralista es aquel dispuesto a evaluar críticamente, con lujo de detalles, evidencias y argumentos en favor de las opciones disponibles. Esto es lo que Mignolo y quienes se autodenominan decoloniales no hacen. $Y$ no lo hacen porque, para empezar, simplifican grotescamente la realidad combatiendo contra un supuesto "pensamiento único", cuando en realidad (en particular en el mundo académico contemporáneo) hay una enorme y creciente diversidad de perspectivas teóricas. ¿Quién le negaría hoy a Mignolo el derecho a aliarse con las propuestas de Pacari, Patzi Paco o Williams, y no con las de Blackburn o Bourdieu? Lo que quizá se le solicite es que presente argumentos en favor de esa opción. ${ }^{39}$ Pero el único argumento que Mignolo presenta para fundar su preferencia es el lugar de nacimiento o el color de la piel de cada uno. Como argumento no sólo es insuficiente, sino que se funda en la falacia de la descalificación ad hominem..$^{40}$

38 W. Mignolo, "La idea de América Latina ("La derecha, la izquierda y la opción decolonial)", op. cit., pp. 261-262.

39 Digo "quizá" porque en el mundo académico hay mucha pluralidad pero escaso intercambio. Lo usual es que las distintas "tribus" se desarrollen una al lado de la otra ignorándose mutuamente.

40 Una creencia dentro del mundo académico es que las mejores obras son las que alcanzan mayor reconocimiento al interior de la comunidad. Por supuesto que esto no es estrictamente cierto: como todo el mundo sabe, ciertos grupos étnicos o lingüísticos poseen un innegable privilegio

\section{Según Mignolo:}

el desprendimiento es el punto de partida de prácticas y concepciones de la economía y la política, la ética y la filosofía, la tecnología y la organización de la sociedad en las cuales no será el progreso y el crecimiento económico, por sobre el bienestar de las personas, lo que motive nuestros quehaceres..$^{41}$ La opción decolonial propone el desprendimiento de la lógica de la colonialidad -de un horizonte de vida en el que se vive para trabajar en lugar de trabajar para vivir... ${ }^{42}$

Personalmente, considero que el bienestar de las personas debe estar por encima del progreso y el crecimiento económico y que el horizonte de vida no debería ser vivir para trabajar. Pero no veo que eso entrañe la necesidad de ningún "desprendimiento" esencial. Yo puedo asumir esas perspectivas partiendo de la tradición marxista con la que me identifico. Y no veo por qué alguien que parta del liberalismo, del cristianismo, del islamismo, del induísmo o del anarquismo no podría llegar a coincidir.

\section{Opción decolonial e implicancias ideológicas}

El punto fuerte de las obras producidas hasta ahora en el marco de la opción decolonial no es la erudición, el rigor lógico ni la solvencia teórica. Su fortaleza se halla en su capacidad políticointelectual para resultar atractiva entre grupos sociales (aunque hasta ahora fundamentalmente intelectuales) que sufren diferentes formas de discriminación étnico-racial y que sienten repulsa por las formas de explotación y opresión de diferente tipo que caracterizan a las sociedades contemporáneas. Su campo es la denuncia, antes que la comprensión; las implicaciones ideológicas, antes que las hipótesis explicativas; la retórica, antes que la teoría. En esos terrenos se ha revelado potente. Pero como al interior de la opción decolonial no se distinguen usualmente estos planos, considerando toda actividad intelectual como algo homogéneo, sus críticas y propuestas se presentan en una confusa mezcolanza de niveles analíticos, operaciones intelectuales y dimensiones de la realidad. Esto hace sumamente dificultosa cualquier evaluación crítica, e incluso separar la paja del trigo. Así como el marxismo dogmático cosechaba adhesiones (y por cierto que no pocas) mezclando sin ton ni son planos y

basado en sutiles y muchas veces inconscientes formas de prejuicio. Podríamos decir que hay "trampas" por medio de las cuales los miembros de estos grupos tienden a ser más reconocidos, con cierta independencia de las cualidades de sus obras. Ante este situación, en lugar de reclamar que se acaben las "trampas", Mignolo parece reclamar "hagamos trampa también nosotros", ensalcemos a los "nuestros" por ser "nuestros", sin que importe mucho la riqueza real de sus contribuciones.

41 W. Mignolo, Desobediencia epistémica, op. cit., p. 34.

42 W. Mignolo, "La idea de América Latina..., op. cit., p. 267. 
niveles, difundiendo disparates como la "lógica dialéctica" o la "ciencia proletaria" y se protegía de las críticas acusando a los críticos de burgueses; los partidarios de la opción decolonial incurren en mezcolanzas semejantes y absurdos equiparables, pero protegiéndose no en nombre del proletariado sino de los colonizados: sus críticos serán necesariamente gente atrapada en el paradigma eurocentrado. ${ }^{43}$

La opción decolonial parece ser en gran medida una consecuencia de la desilusión por el fracaso de los experimentos anticoloniales y socialistas del siglo XX. Ante un mundo cuyas iniquidades se demuestran más perdurables de lo que se hubiera esperado y deseado, es fácil caer en la tentación de hallar respuestas simples a las complejidades y ambigüedades de cualquier proyecto de liberación. John Holloway creyó explicar todos los males a partir del poder estatal, y creyó hallar una receta política capaz de evitar el callejón sin salida de los socialismos del siglo XX: "cambiar el mundo sin tomar el poder".44 Con simplismo semejante, la opción decolonial cree que todo se explica por una matriz colonial de poder que todo lo abarca. Son respuestas demasiado simples para problemas demasiado complejos, aunque se fundan en algunos hechos efectivamente observables: el fracaso de construir el socialismo, la persistencia del racismo y el etnocentrismo.

Con criterio semejante y equiparable simplismo, visto el hecho indudable del arraigado machismo y la perdurabilidad del patriarcado en la mayor parte de las sociedades conocidas, una feminista podría plantear que no habrá liberación para las mujeres si no se rompe con los marcos epistémicos no sólo de Occidente, sino también indúes, budistas, islámicos, andinos, mapuche, etc. $Y$ un obrero clasista, observando el hecho evidente de la omnipresencia de la explotación de clases en los últimos cinco mil años, podría sostener que hay que desprenderse de todos esos marcos epistémicos y sumarles el decolonial, el marxista y el feminista, que tampoco han acabado con la explotación y opresión de clases (e incluso han servido, consciente o inconscientemente, para perpetuarlas). Quizá habría que romper con todos los marcos epistémicos: dejar de pensar. ¿Por qué no? Después de todo, sólo desde una perspectiva especiocéntrica es tan importante el pensar: no parece ser una actividad especialmente valorada por los lagartos o las mariposas. Y dado que nuestra especie amenaza con destruir el planeta... quizás deberíamos dejar de pensar.

Pero no, no renunciemos a pensar. Como dijera el intelectual mapuche José Marimán, "no se combaten fiebres rompiendo termómetros". El mundo tiene componentes horribles, y ciertamente a veces dan ganas de gritar: ¡paren el mundo que

43 Por supuesto que hay dogmatismos y disparates en todas las tradiciones políticas e intelectuales. He dado el ejemplo del marxismo porque soy marxista, y prefiero ver la paja en el ojo propio antes que en el ajeno.

44 John Holloway, Cambiar el mundo sin tomar el poder, Buenos Aires, Herramienta/Universidad Autónoma de Puebla, 2002. me bajo! Pero nadie puede parar al mundo y, sin dejar de sentir indignación por las injusticias tan grandes que nos rodean, debemos asumir la responsabilidad ético-político-intelectual de alcanzar la mayor claridad posible sobre sus causas. $Y$ esto entraña algo mucho más complejo que combatir retóricas o desarrollar contraretóricas.

Como ya tuve oportunidad de señalar, hallar claras precisiones y delimitaciones de los conceptos decoloniales es en general una búsqueda infructuosa. Más bien, lo que los caracteriza es una interminable proliferación de nuevos términos, la búsqueda frenética de un lenguaje propio: colonialidad, matriz colonial de poder, patrón colonial, pensamiento fronterizo, transmodernidad, pensamiento heterárquico, pensamiento abisal, hybris del punto cero, transculturalidad, epistemología otra, racionalidad otra, epistemología del sur, epistemología de las ausencias, desprendimiento, ego-logía, corpo-política, etc. Sin embargo, tras estas palabras rara vez hay un concepto claro y distinto (ningún pecado cartesiano quieren cometer los teóricos y las teóricas decoloniales). En general, no son más que una nueva palabra para un viejo concepto o un matiz reivindicado como total ruptura o una noción intuitivamente plausible pero que no es conceptualmente especificada o una metáfora. Son términos cuya funcionalidad reside más en generar identidad (decolonial, en quien habla así) que en aclarar algún problema empírico o conceptual. Antes que conceptos de una teoría, son la jerga de un grupo.

La falta de rigor erudito es una constante en las obras de Mignolo, de Sousa Santos y Quijano. E insisto: ya no son una corriente emergente a la que se puede dar el beneficio de la duda. Para cualquier persona que tenga una formación más o menos intensa en algún campo o problemática específica, las afirmaciones decoloniales referidas al mismo le parecerán, en general, poco convincentes. Demuestran que no se ha tenido voluntad de estudiar esos problemas y esas materias en sus propios términos. ¡Claro, hacerlo sería sucumbir ante la episteme eurocentrada! Sin embargo, un auténtico diálogo interepistémico implica el esfuerzo de estudiar con minuciosidad las diferentes teorías e interpretaciones. Y presupone la capacidad de poner en suspenso las propias premisas y hacer el esfuerzo de comprender los argumentos del otro en sus propios términos (antes que invalidarlos porque parten de premisas diferentes). Hecho esto (de ambas partes) es posible procurar evaluar los pro y contra de las diferentes perspectivas, asumiendo que todas las partes deben presentar evidencia de sus afirmaciones $\mathrm{y}$ argumentos en su favor. ${ }^{45} \mathrm{Y}$ bien en los textos decoloniales las

45 Un excelente tratamiento de la problemática, las dificultades y la posibilidad de un auténtico diálogo inter-epistémico se encuentra en León Olivé, "Racionalidad y relativismo: relativismo moderadamente radical", en León Olivé (comp.), Racionalidad. Ensayos sobre la racionalidad en ética y política, ciencia y tecnología, México, Siglo XXI, 1988. 
evidencias son escasas, pero sobre todo en lugar de argumentos hay afirmaciones cuya justificación rara vez se proporciona. Los textos decoloniales abordan una infinidad de temas y es imposible tener un conocimiento meticuloso de todos ellos. En cualquier caso, cada vez que se refieren a cuestiones que conozco en detalle -como el marxismo, la modernidad o el Renacimientosus afirmaciones son entre unilaterales y caricaturescas. Pero, del otro lado, no deja de ser sintomático y profundamente significativo que, a pesar de sus reivindicaciones de "otros" saberes, rara vez se encuentra en sus escritos una exposición detallada de las "cosmovisiones otras". Y lo mismo sucede con las obras de los autores y autoras a los que se ensalza (como Waman Poma, Frantz Fanon o Gloria Anzaldúa): nunca se nos ofrece un examen crítico detallado de las mismas.

Por consiguiente, la superficialidad con la que se rechaza la episteme occidental o la retórica de la modernidad de las que habría que desprenderse es equivalente a la superficialidad con que se abraza a los "pensamientos otros": muy rara vez se estudia con detalle qué están pensando los miembros concretos de grupos étnicos concretos. Un indio abstracto -reencarnación del buen salvaje- reemplaza a los mapuche, quom o tojolobales reales. En las contadísimas ocasiones en que se incorporan sus voces, se las incorpora sin discusión: ¿discutirlas sería una muestra de colonialidad? Más que diálogo inter-epistémico o intercultural, la opción decolonial parece una forma (¿otra?) de paternalismo. Según la apropiación genealógico/mitológica realizada por Mignolo:

las teorías críticas descoloniales emergen de las ruinas de los lenguajes de las categorías de pensamiento y de las subjetividades (árabe, aymará, hindi, créole francesa e inglesa en el Caribe, afrikaan, etcétera) que han sido constantemente negadas por la retórica de la modernidad y la aplicación imperial de la lógica de la colonialidad. ${ }^{46}$

Pero lo cierto es que la concepción decolonial es el producto de académicos fuertemente implantados en Estados Unidos: más de la mitad de los miembros del grupo modernidad/colonialidad trabaja en universidades estadounidenses total o parcialmente. $Y$ aunque se presenten como niños terribles en el mundillo universitario, en verdad reproducen de facto todas las prácticas académicas, incluso muchas no justificables, por ejemplo: aceptar la eternización de estudios de posgrado y la mercantilización de la educación; dispensarse mutuamente obsequiosas citas (o insultos, cuando la amistad se quiebra); rehuir la crítica a autores contemporáneos de sus propios campos (un riesgo que académicamente se esquiva para no ganar enemigos que pongan palos en la carrera, aunque es también un lujo que se pueden permitir quienes ya tienen "la carrera hecha"); armar vínculos entre miembros de diferentes franjas etarias marcados por una lógica de séquito; impulsar la proliferación de la escritura de breves papers (tan útiles para hacer "carrera" como inútiles para discutir meticulosamente un problema) en detrimento de las extensas obras unitarias; caer en la eterna reescritura (refrito) de los mismos textos, etc.

Aunque seguramente es más que ello, en una medida considerable, parafraseando al intelectual palestino Edward Said, podríamos decir que la opción decolonial parece ser la imagen invertida (la versión "crítica" o contestaria) del:

crudo reduccionismo de lo que se ha dado en llamar "choque de civilizaciones", una simplificación de la realidad originada en el mundo universitario norteamericano que sirve a los propósitos de dominación de Estados Unidos como superpotencia tras el 11 de septiembre, pero que no trasmite la verdad de cómo las civilizaciones y culturas se solapan, confluyen y se nutren unas a otras. ${ }^{47}$

A diferencia del marxismo, que surgió fuera del mundo universitario pero desarrolló una tradición de enorme sutileza y riqueza intelectual, al tiempo que conformó o ayudó a conformar (no sólo intelectual sino prácticamente) al primer movimiento social moderno (el movimiento obrero); y a diferencia de pensadores como Fanon, que comprometieron no sólo sus ideas sino su cuerpo con los movimientos de liberación del siglo $\mathrm{XX}$; la opción decolonial surge del interior mismo del mundo académico, sin grandes sutilezas o riquezas intelectuales y $\sin$ demasiada voluntad por participar prácticamente de manera cotidiana en movimientos sociales o políticos contemporáneos: su mundo es el de las cátedras, los seminarios, los congresos y los viajes alrededor del planeta, cuyas comodidades sólo se abandonan muy de vez en cuando.

La falta de sutileza intelectual, la escasez de erudición, los juicios demasiado tajantes, los yerros históricos; todo podría ser relativizado si se tratara de escritos esencialmente políticos producidos por militantes fuertemente comprometidos con alguna organización, y cuyo propósito fuera incitar a la acción, antes que buscar claridad intelectual; performar retóricamente, más que explicar con riqueza teórica. El problema es que los exponentes de la opción decolonial ni son militantes en situación de riesgo; ni son intelectuales que aporten claridad o sofisticación a los debates. La opción decolonial, pues, tiene mucho de impostura.

\section{Bibliografía}

Barriga, Andrea y Ariel Petruccelli, "Santiago Maldonado: crónica

47 Edward Said, Orientalismo, Barcelona, Debolsillo, 2004, p 10. 
de una desaparición forzada", Sin Permiso, 2017, disponible en http://www.sinpermiso.info/textos/santiago-maldonado-cronicade-una-desaparicion-forzada.

- "Santiago Maldonado: entre la montaña de mentiras y la larga marcha hacia la verdad", Sin Permiso, 2017, disponible en http://www.sinpermiso.info/textos/santiago-maldonado-entrela-montana-de-mentiras-y-la-larga-marcha-hacia-la-verdad-en-laargentina.

Chaudhuri, Kirti N., The Trading World of Asia and the English East India Company, 1660-1760, Cambridge, Cambridge University Press, 1978.

Castro-Gómez, Santiago y Ramón Grosfoguel, El giro decolonial. Reflexiones para una diversidad epistémica más allá del capitalismo global, Bogotá, Siglo del Hombre Editores, 2007.

De Sousa Santos, Boaventura, Una epistemología del sur, México, Siglo XXI, 2009.

Fanon, Frantz, Los condenados de la tierra, México, Fondo de Cultura Económica, 2009.

Gellner, Ernest, El arado, la espada y el libro. La estructura de la historia humana, Barcelona, Península, 1988.

Grosfoguel, Ramón, "Entrevista a Ramón Grosfogel", Polis. Revista Latinoamericana, $n^{\circ}$ 18, 2007.

— "Entrevista a Ramón Grosfogel", Analéctica, Año 0, n 1, 2013.

Guamán Poma de Ayala, Felipe, Nueva Crónica y buen gobierno, Caracas, Biblioteca Ayacucho, 1980.

Holloway, John, Cambiar el mundo sin tomar el poder, Buenos Aires, Herramienta/Universidad Autónoma de Puebla, 2002.

Jones, Eric, The European Miracle: Environments, Economies, and Geopolitics in the History of Europe and Asia, Cambridge, Cambridge University Press, 1989.

Marimán, José, Autodeterminación. Ideas políticas mapuche en el albor del siglo XXI, Santiago de Chile, LOM, 2012.

- Awkan tañi müleam Mapu kimün. Mañke ñi pu Kintun, Santiago de Chile, Centro de Estudios Rümtun - Fundación Heinrich Böll Cono Sur, 2017.

Mignolo, Walter, La idea de América Latina, Barcelona, Gedisa, 2005.

- "La idea de América Latina ("la derecha, la izquierda y la opción decolonial)", Crítica y Emancipación, n. 2, 2009.

- Desobediencia epistémica. Retórica de la modernidad, lógica de la colonialidad y gramática de la descolonialidad, Buenos Aires, Ediciones del Signo, 2010.

Newton-Smith, William H., La racionalidad de la ciencia, Barcelona, Paidós,1987.

O' Gorman, Edmundo, La invención de América, México, Fondo de Cultura Económica, 1995.

Olivé, León (comp.), Racionalidad. Ensayos sobre la racionalidad en ética y política, ciencia y tecnología, México, Siglo XXI, 1988.

Petruccelli, Ariel, Pablo Scatizza y Mauricio Suraci, "Roca, su monumento y las barbaries de Romero", Viento del Sur, 2012, disponible en http://www.revistavientodelsur.com.ar/roca-sumonumento-y-las-barbaries-de-romero/.

Petruccelli, Ariel y Pablo Scatizza, "Una posición frente a la resistencia a izar el wenufoye en San Martín de los Andes", Izquierda Diario, 2014, disponible en https://www. laizquierdadiario.com/Una-posicion-frente-a-la-resistencia-porizar-el-wenufoye-en-la-Plaza-San-Martin.

Petruccelli, Ariel, "Los mapuche y un discurso de terror", Izquierdad Diario, 2017, disponible en https://laizquierdadiario. com/Los-mapuche-y-un-discurso-de-terror.

Pomeranz, Kenneth, The Great Divergence: China, Europe and the Making of the Modern World Econmy, New Jersey, Princeton University Press, 2000.

Quijano, Aníbal, Modernidad, identidad y utopía en América Latina, Lima, Sociedad y política Ediciones, 1988.

- (selección y prólogo de Danilo Assis Clímaco), Cuestiones y horizontes. De la dependencia histórico-estructural a la colonialidad/descolonialidad del poder, Buenos Aires, Clacso, 2014.

Said, Edward, Orientalismo, Barcelona, Debolsillo, 2004.

Sacristán, Manuel, Sobre Marx y marxismo, Barcelona, Icaria, 1983.

- Conferencias 1978-1983, Barcelona, El Viejo Topo, 2005. Stern, Steve, Los pueblos indígenas del Perú y el desafío de la conquista española, Madrid, Alianza, 1986.

Wallerstein, Immanuel, El moderno sistema mundial, t.l, México, Siglo XXI, 1981. 


\section{Resumen}

Este trabajo contiene un análisis critico de la llamada opción decolonial, atendiendo a sus dimensiones teóricas, epistemológicas, políticas e institucionales. Compartiendo la voluntad de cuestionar y superar indudables asimetrías en el terreno intelectual, producto de una larga historia de colonización, el texto procura mostrar las falencias de la opción decolonial como crítica del colonialismo epistémico pero, sobre todo, como propuesta de superación. La perspectiva desde la que se desarrolla la crítica es la de un marxismo heterodoxo.

Palabras clave: opción decolonial, cultura, marxismo, eurocentrismo, episteme.

\section{Abstract}

This work contains a critical analysis of the so-called decolonial option, taking into account its theoretical, epistemological, political and institutional dimensions. Sharing the will to question and overcome undoubted asymmetries in the intellectual field, the product of a long history of colonization, the text tries to show the shortcomings of the decolonial option as a critique of epistemic colonialism but, above all, as a proposal for overcoming it. The perspective from which the criticism is developed is that of a heterodox Marxism.

Keywords: decolonial option, culture, Marxism, Eurocentrism, episteme.

Recibido: 25/03/2020

Aceptado: 12/08/2020 